\title{
POLÍTICA DE SEGURANÇA DOS EUA PARA A AMÉRICA LATINA NO GOVERNO OBAMA: HEGEMONIA E AJUSTES TÁTICOS'1
}

\author{
U.S. SECURITY POLICY TOWARD LATIN AMERICA IN THE OBAMA \\ ADMINISTRATION: HEGEMONY AND TACTICAL ADJUSTMENTS
}

DOI: $10.5380 /$ cg.v10i2.80173

João Estevam dos Santos Filho

\begin{abstract}
Resumo
O presente trabalho tem como objetivo compreender qual foi o sentido da política de segurança dos EUA para a América Latina durante o governo de Barack Obama. A hipótese aqui proposta é a de que, nesse período, a política de segurança sofreu ajustes de ordem "tática" com o objetivo de manter as relações hegemônicas com os países da região na dimensão de segurança. Especificamente, é entendido que esses ajustes consistiram em: relações menos militarizadas; implementação de projetos de desenvolvimento socioeconômico e menor utilização do discurso antiterrorista. Para a realização deste trabalho, foi feita análise de dados quantitativos coletados em bases de dados internacionais; análise documental de relatórios e políticas de segurança do governo dos EUA e revisão de literatura sobre relações EUA-América Latina. Os resultados obtidos demonstram que houve de fato uma redução no grau de militarização das iniciativas de cooperação em segurança dos EUA com os países da região, ao mesmo tempo em que a ênfase foi posta mais na agenda antidrogas do que na de antiterrorismo. Assim, a conclusão do trabalho é que há indícios de ajustes pontuais da política de segurança dos EUA para a América Latina a fim de manter sua posição hegemônica em um novo contexto internacional.
\end{abstract}

Palavras-chave: Estados Unidos; Governo Obama; América Latina; Política de Segurança.

\begin{abstract}
This paper aims to understand the direction of U.S. security policy toward Latin America during Barack Obama's administration. The hypothesis proposed here is that, during this period, the security policy suffered "tactical" adjustments with the objective of maintaining the hegemonic relations with the countries of the region in the security dimension. Specifically, it is understood that these adjustments consisted of: less militarized relations; implementation of socioeconomic development projects, and less utilization of the antiterrorist discourse. To conduct this work, there was analysis of quantitative data collected from international databases; documentary analysis of U.S. government security reports and policies, and literature review about US-Latin American relations. The results obtained show that there has indeed been a reduction in the degree of militarization of the USA security cooperation initiatives with countries in the region, at the same time that the emphasis has been put more on anti-drug agenda in opposition to the anti-terrorist agenda. Therefore, the

\footnotetext{
${ }^{1}$ Artigo originado de uma pesquisa financiada com recursos da Fundação de Amparo à Pesquisa do Estado de São Paulo (FAPESP). Este artigo está licenciado sob a Licença Creative Commons Attribution (CC BY 4.0), sendo permitido o compartilhamento com reconhecimento da autoria e publicação inicial nesta revista.

${ }_{2}^{2}$ Doutorando pelo PPGRI San Tiago Dantas. Mestre em Relações Internacionais pelo mesmo programa. Bacharel em Relações Internacionais pela UFRGS. Membro do Grupo de Estudos de Defesa e Segurança Internacional (GEDES). E-mail: joaoestevamo8@gmail.com. ORCID: https://orcid.org/o000-0003-2202$\underline{\mathrm{o} 89 \mathrm{X}}$.
} 
conclusion of this work is that there is evidence of occasional adjustments in USA security policy for Latin America in order to maintain its hegemonic position in a new international context.

Keywords: United States; Obama Government; Latin America; Security Policy.

\section{INTRODUÇÃO}

Apesar de haver uma quantidade significativa de trabalhos que tratam da política externa norte-americana para a região latino-americana durante o governo de Barack Hussein Obama (2009-2017) (AYERBE, 2010; WEISBROT, 2011; MUÑOZ，2015； LOWENTHAL， 2016; PECEQUILO; FORNER, 2017a), poucos se detiveram em uma análise mais específica quanto à política de segurança dos Estados Unidos da América (EUA) para a América Latina durante o período, fazendo-se necessário o preenchimento dessa lacuna. Nesse sentido, o presente trabalho tem como objetivo compreender o sentido da política de segurança dos EUA para a região durante o governo Obama, tendo como hipótese proposta a de que, nesse período, ela sofreu ajustes de ordem "tática" com o objetivo de manter as relações hegemônicas com os países da região. Especificamente, é entendido que esses ajustes consistiram em: relações menos militarizadas; implementação de projetos de desenvolvimento socioeconômico e menor utilização do discurso antiterrorista.

O referencial teórico escolhido para a análise refere-se ao conceito de hegemonia, baseado na perspectiva estabelecida pelos trabalhos de Robinson (1996; 2008), Avilés (2017) e Biegon (2017), que estão vinculados a uma abordagem neomarxista das Relações Internacionais. Desse modo, a hegemonia é entendida como um tipo de relação de poder estabelecida por classes dirigentes do país dominante sobre a sociedade do país subalterno, com aceitação das elites políticas desse último. Por sua vez, para a realização desta pesquisa, foi realizada, em primeiro lugar, a análise de dados quantitativos referentes aos recursos financeiros provenientes dos programas de assistência de segurança dos EUA para os países da região. Em segundo lugar, foi feita uma análise documental de relatórios de políticas de segurança do governo norte-americano para os países latino-americanos. Por último, revisou-se a literatura referente às relações entre EUA e América Latina.

O presente trabalho está divido em quatro seções, incluindo esta introdução. A segunda seção trata da abordagem teórica com que se analisará as ações do governo Obama na América Latina e contextualiza essa política de segurança com a política externa da administração. A terceira faz uma análise quanto aos dados coletados sobre os mecanismos de assistência de segurança para a América Latina, apresentando os casos de Colômbia, México, América Central e Caribe para refinar a investigação. Nesse sentido, serão analisados principalmente as mudanças que o governo Obama realizou nos programas de assistência de segurança para cada um desses casos. Por fim, na última seção, serão apresentados um resumo da análise realizada e as considerações finais. 


\section{HEGEMONIA E POLÍTICA EXTERNA DO GOVERNO OBAMA}

Ao analisarmos a literatura sobre relações entre EUA e América Latina, é assumido que desde a segunda metade do século XX tem sido verificado um contexto de relações hegemônicas de poder (AYERBE, 2002; KASSAB, 2015; TULCHIN, 2016; BIEGON, 2017; O’KEEFE, 2018). Entretanto, parte desses autores têm compreendido que a hegemonia norte-americana na região tem declinado desde o final da Guerra Fria, devido a uma série de fatores, dentre os quais destacam-se: capacidade de agência dos Estados latino-americanos, sobretudo os sul-americanos, através de instituições políticas regionais (TULCHIN, 2016), a presença crescente de atores extrarregionais, com destaque para China e Rússia (KASSAB, 2015), e o declínio do poder norte-americano em âmbito global.

Entretanto, alguns autores sustentam a ideia de permanência dessa hegemonia, apesar das reações por parte dos Estados latino-americanos nas décadas de 2000 e 2010. Desse modo, Chodor (2014) afirma que a permanência do neoliberalismo mesmo diante da chamada "Onda Rosa" é um indício da hegemonia das elites políticas norte-americanas. Por sua vez, Biegon (2017) identifica a continuação da hegemonia norte-americana em quatro dimensões fundamentais, quais sejam, economia, instituições políticas, segurança e ideologia. Também Avilés (2017) afirma que a hegemonia dos EUA na região pode ser vista no caso da influência das elites políticas e corporativas do país nas políticas de segurança dos países latino-americanos, particularmente, no caso da chamada "guerra às drogas", desde a década de 1970. Também Robinson (2008) diz que a ingerência norte-americana sobre a política interna dos países latino-americanos, incluindo na esfera securitária, é um indício de manutenção de relações hegemônicas.

Segundo esses autores, pode-se compreender a definição de hegemonia como um tipo de relação de poder envolvendo a influência das elites políticas norte-americanas sobre as dos países da região a fim de garantir um ordenamento da ordem interna favorável a seus interesses, particularmente aqueles ligados ao capital transnacional (ROBINSON, 1996; 2008; AVILÉS, 2010; 2017; CHODOR, 2014; BIEGON, 2017). Apesar desses objetivos gerais, essas relações hegemônicas também passam por modificações de caráter "tático" em virtude tanto das mudanças das elites políticas norte-americanas de uma administração para a outra quanto do contexto estrutural em que estão inseridas no nível internacional (VAN APELDOORN; DE GRAAF, 2014). Desse modo, é importante compreender o caráter geral da política externa dos EUA na administração Obama e, a partir desse contexto, focar especificamente no caso da política de segurança para a América Latina, a fim de entender que variações táticas foram feitas por esse governo para manter a hegemonia norte-americana diante do novo contexto internacional - variações essas que serão objeto de análise neste trabalho.

O início do governo Obama foi marcado por um cenário bastante complexo tanto na política doméstica quanto na externa. Internamente, os EUA enfrentavam a maior crise financeira desde a de 1929, com um grande aumento do desemprego, retração da atividade econômica e dificuldades 
apresentadas pelas principais instituições financeiras do país. Externamente, o governo norteamericano via-se envolvido em duas guerras extremamente custosas e impopulares (Iraque e Afeganistão), com uma política de defesa voltada para o combate ao terrorismo internacional sobretudo contra a Al-Qaeda - e necessitando lidar com uma China emergente e com relações difíceis com a Rússia. Por outro lado, o país sofreu certo desgaste internacional devido às ações unilaterais e à retórica belicista do governo de George Bush (2001-2009) (LOWENTHAL, 2011). Desse modo, van Apeldoorn e de Graaf (2014) afirmam que o governo Obama necessitou atualizar sua grande estratégia para lidar com o novo ambiente internacional.

É nesse contexto que, em 2010, o governo recém-eleito publicou a sua primeira Estratégia Nacional de Segurança, na qual foram estabelecidas as principais linhas que guiariam a atuação internacional dos EUA para a esfera de segurança. Nesse sentido, foram enfatizados os seguintes pontos: 1) romper, desmantelar e derrotar a Al-Qaeda e seus grupos terroristas parceiros no Afeganistão, no Paquistão e ao redor do mundo; 2) reverter a proliferação de armamento nuclear e biológico; 3) avançar a paz, segurança e oportunidade no Oriente Médio; 4) investir no fortalecimento das capacidades dos parceiros globais; e 5) segurança do ciberespaço. Além disso, o documento reitera o objetivo de consolidar a liderança global norte-americana, mas enfatizando a necessidade de trabalhar com instituições internacionais, parceiros regionais e recorrendo ao multilateralismo. Também cabe ressaltar o tom conciliatório usado com relação à Rússia, China e outros países emergentes, como o Brasil, afirmando a necessidade de trabalhar com eles, inclusive em fóruns internacionais como o G-20 comercial (UNITED STATES OF AMERICA, 2010).

Já na Estratégia Nacional de Segurança de 2015, o governo Obama passou a adotar um tom mais ofensivo, buscando demonstrar a importância de os EUA buscar recuperar os espaços perdidos ao longo da primeira década do presente século. Nesse sentido, o documento enfatiza as seguintes áreas de atuação: 1) combate à ameaça do terrorismo - com foco novamente no Afeganistão e a assistência dada pelos países da Organização do Tratado do Atlântico Norte (OTAN) a esse país, sobretudo em forma de treinamento, equipamento e assistência técnica; 2) a construção de capacidades para prevenção de conflitos - destacando a anexação da Crimeia pela Rússia em 2014; 3) a prevenção contra a proliferação e o uso de armamentos nucleares e de destruição em massa; 4) o combate à mudança climática e segurança de espaços compartilhados (ciberespaço, mar, ar e espaço sideral). Nesse último tópico, percebe-se uma preocupação com a presença chinesa no Mar do Sul da China e no desenvolvimento de equipamentos espaciais de grande relevância. (UNITED STATES OF AMERICA, 2015). Assim, o tom conciliatório com os países emergentes (sobretudo com Rússia e China) passaram a ganhar conotações mais belicosas ou, ao menos, mais cautelosas.

Portanto, foi percebida durante o governo Obama a passagem de uma postura reativa frente às mudanças no sistema internacional para uma mais ofensiva, buscando recuperar espaços antes perdidos tanto devido à crise econômica de 2008-2009 quanto à emergência de novos atores internacionais de grande peso econômico e estratégico-militar (PECEQUILO; FORNER, 2017a). 
Essa visão é corroborada por van Apeldoorn e de Graaf (2014), para quem a chamada grande estratégia norte-americana foi caracterizada, por um lado, pelo reconhecimento dos limites de exercício de poder dos EUA no sistema internacional - sobretudo após a perda de legitimidade e os constrangimentos internos resultantes da grande estratégia do governo Bush -, que levou as elites políticas ligadas à nova administração a darem importante ênfase à economia, à cooperação multilateral e ao engajamento com países aliados. Por outro, o governo Obama também foi caracterizado pelo uso coercitivo (inclusive com a manutenção do discurso de "ataque preventivo") para manter a ordem liberal internacional - o que os autores denominam política de "Portas Abertas", ou seja, a manutenção do livre fluxo financeiro e de mercadorias no sistema internacional. É desse modo que a política de segurança estadunidense adotou medidas de enfrentamento às grandes potências rivais (China e Rússia) e continuou sua política agressiva no Oriente Médio.

Nesse sentido, já a partir de 2011, os EUA buscaram uma nova reinserção na região da ÁsiaPacífico no que ficou conhecido como "Pivô para a Ásia". Essa iniciativa contaria com seis linhas de ação: fortalecimento das alianças de segurança bilaterais; aprofundamento das relações com os países emergentes já em andamento, como a China; engajamento em instituições regionais multilaterais; expansão do comércio e do investimento; construção de uma ampla presença militar e avanço na democracia e nos direitos humanos (CLINTON, 2011). Nessa nova política de aumento da presença estadunidense na Ásia, o aspecto militar teve um peso relevante, com a implementação de medidas agressivas, como o emprego de tropas na Austrália, de embarcações em Singapura e estabelecimento de novas áreas de cooperação militar com as Filipinas. Ao mesmo tempo, a atuação militar estadunidense na Ásia-Pacífico contou com uma distribuição mais ampla de forças; com o aumento da flexibilidade do emprego das tropas e, por fim, com a melhora nas capacidades dos parceiros regionais, através de mecanismos de assistência em segurança e de operações contraterroristas, antidrogas e contrainsurgentes cooperativas (MANYIN et al., 2012).

Por outro lado, as atenções estratégicas dos EUA voltaram-se para o leste europeu a partir de 2013, com a crise política na Ucrânia, que acabou por levar à queda o presidente pró-Rússia Petro Poroshenko e, posteriormente, resultou na anexação da península da Crimeia pela Rússia como reação à aproximação ucraniana com o Ocidente no governo de Víktor Yanukóvytch. Desse modo, a partir de 2015 os EUA passaram a aumentar seus gastos militares na Europa, incluindo mais de US\$ 3,4 bilhões e o posicionamento de novos equipamentos militares, bem como o emprego de uma brigada de combate blindada completa na região (LYMAN, 2016). Além disso, os EUA continuaram a investir no escudo antimísseis da OTAN, com equipamentos e instalações localizados em diversas localidades da Europa, incluindo Polônia, Romênia e o Mar Mediterrâneo3 (PICCOLLI, 2013). Além do Escudo Antimísseis, foi verificado um aumento no número de exercícios conjuntos no âmbito da aliança, bem como a atualização do Plano de Ação de Prontidão (Readiness Action Plan, em inglês),

\footnotetext{
3 Entretanto, segundo o discurso oficial do governo dos EUA, a construção desse Escudo Antimísseis teria como verdadeira finalidade a construção de uma capacidade dissuasória contra o Irã.
} 
que focou no aumento da presença militar aérea, naval e terrestre ao longo da fronteira com a Rússia; no emprego de batalhões multinacionais para os três países bálticos e para a Polônia; no aumento da Força de Resposta da organização de 13.000 para 40.000 militares; na criação de uma unidade conjunta de 5.00o efetivos, dentre outras ações (BROOKE-HOLLAND, 2016; BURTON, 2018).

Por outro lado, ainda que com um enfoque diferente em alguns aspectos em relação à administração anterior, o governo Obama continuou com uma política de segurança voltada também para o combate ao terrorismo, com prioridade dada aos grupos terroristas (a Al-Qaeda, em um primeiro momento e, logo depois, o Estado Islâmico) no Afeganistão e no Paquistão, como foi visto nas Estratégias Nacionais de Segurança de 2010 e de 2015. Assim, as iniciativas militares norteamericanas na guerra global contra o terror continuaram a ocorrer sobretudo no Oriente Médio e Norte da África, assemelhando-se em alguns aspectos com a política antiterrorista da administração anterior (DESCH, 2010). Dessa maneira, ao mesmo tempo em que houve um aumento de recursos para o Paquistão destinados ao combate ao terrorismo, o número de tropas no Afeganistão aumentou nesse período, chegando a atingir o contingente de 100 mil efetivos entre 2010 e 2011 (PECEQUILO; FORNER, 2017b).

No que se refere à situação do Iraque, apesar de ter sido iniciada a retirada das tropas estadunidenses do país a partir de 2010, em 2014 ele voltou ao radar do governo Obama devido ao crescimento da influência e das ações do Estado Islâmico, tanto no Iraque quanto na Síria. Ademais, em que pese tenha havido uma redução do número de tropas dos EUA no Oriente Médio (excetuando-se o Afeganistão), foi verificado um incremento na quantidade de ações militares realizadas com o uso de drones, inclusive no Norte da África (PECEQUILO; FORNER, 2017b). Outro importante fato no governo Obama foi a chamada Primavera Árabe, que contou com a parceria da França, do Reino Unido e da Itália para apoiar os grupos rebeldes na derrubada de Muammar Kadafi, morto em 2011 (JERVIS, 2018).

Portanto, ainda que tenha buscado privilegiar a coordenação política com seus aliados europeus e asiáticos e a pauta econômica tenha sido importante em suas relações externas, no que ficou conhecido como “doutrina Obama” (Del Pero, 2018), a política de segurança do novo presente norte-americano também demonstrou certa agressividade nas questões geoestratégicas envolvendo a competição com China e Rússia e as instabilidades do Oriente Médio. Essas medidas, por sua vez, estiveram ligadas a uma busca por retomar a capacidade de exercício de poder norte-americano que, apesar de privilegiar, até certo ponto, determinadas ações menos duras, não abdicou de sua capacidade de emprego das forças coercitivas. Ao seu turno, esse contexto geral contrasta com o caso latino-americano, no qual (à exceção do golpe de Honduras, em 2009) a tática de manutenção de relações hegemônicas de poder esteve mais relacionada a uma política menos militarizada - ao menos do ponto de vista da assistência de segurança quantitativa - e à maior ênfase na implementação de projetos de desenvolvimento socioeconômico, como se verá na próxima seção. 


\section{POLÍTICA DE SEGURANÇA PARA A AMÉRICA LATINA}

A dimensão securitária da hegemonia norte-americana na América Latina deve ser entendida não apenas como o emprego direito ou indireto de capacidades coercitivas, como no caso das invasões ao Panamá (1989) e ao Haiti (1994), ou como nas ações ligadas à crise centro-americana, durante a década de 1980 - conforme entendido por Biegon (2017). Mais do que isso, essa dimensão da relação de poder hegemônica pode manifestar-se por meio da influência militar que pode ocorrer fundamentalmente em três níveis: o tecnológico, por meio da exportação de equipamentos militares; o doutrinário-ideológico, definindo o inimigo a ser combatido pelos aparatos de segurança (sobretudo as forças armadas) dos Estados latino-americanos - em coordenação com os aparatos norte-americanos -; e, por último, o político-institucional, que tem como objetivo gerar compromissos das elites políticas latino-americanas por meio da criação de mecanismos regionais de coordenação em matéria de segurança. Desse modo, por meio dessas ações, os dirigentes norteamericanos conseguem influenciar a própria estrutura organizacional das forças armadas da região, bem como seu componente doutrinário, determinando também seu papel político (KALDOR, 1986). É preciso dizer, entretanto, que já antes da década de 1990 a influência norte-americana na área de segurança se dava na América Latina por meio de instituições regionais chave, como a Junta Interamericana de Defesa (JID), a Organização dos Estados Americanos (OEA) e o Tratado Interamericano de Assistência Recíproca (TIAR), que foram criados no escopo da Guerra Fria.

Desse modo, a fim de se ter uma melhor dimensão sobre a política de segurança dos EUA para a América Latina nesse período, serão analisados dados relativos à assistência aos países da região nessa área, particularmente, os valores dos recursos transferidos, o número de militares treinados e os valores das compras de armamentos estadunidenses. Além disso, será dado um foco mais específico à Colômbia, ao México, à América Central e ao Caribe, através de seus respectivos programas de assistência de segurança - Plano Colômbia, Iniciativa Mérida, Iniciativa de Segurança Regional da América Central (CARSI, na sigla em inglês) e Iniciativa de Segurança da Bacia do Caribe (CBSI, na sigla em inglês). Esses países foram escolhidos para análise na medida em que foram os principais receptores do auxílio dos EUA (SECURITY ASSISTANCE MONITOR, 2018a).

No que tange aos aspectos quantitativos vistos durante o período Obama, verificou-se uma redução em níveis absolutos do montante de recursos destinados à assistência de segurança para a região. Desse modo, enquanto em 2010 essa quantia alcançava o valor de US\$ 1,2 bilhões, em 2014, esse número foi reduzido para US\$ 727,6 milhões - mas subindo para US\$ 998,5 milhões em 2016. Em relação aos dois maiores receptores ${ }^{4}$ (Colômbia e México, respectivamente), também estes

4 Os dados quantitativos para a América Central e Caribe estão incompletos, não sendo possível, portanto, observá-los de maneira seriada. 
tiveram uma queda significativa nos valores recebidos: no primeiro caso, a redução foi de US $\$ 437,3$ milhões para US\$239,8 milhões; já para o segundo, foi de US\$ 291,7 milhões para US\$ 111,4 milhões (SECURITY ASSISTANCE MONITOR, 2018a).

No que se refere especificamente à assistência no combate ao terrorismo, verifica-se uma diminuição no programa destinado especificamente a esse setor - o Combating Terrorism Fellowship Program (CTFP, na sigla em inglês) -, caindo de US\$ 4,9 milhões para 2,9 milhões entre 2010 e 2016, embora esse valor tenha permanecido relativamente estável entre 2010 e 2014. Já no que se refere aos Programas de Não-Proliferação, Antiterrorismo, Desminagem e Relacionados, houve uma queda de US \$ 18,1 milhões para US \$ 8,5 milhões. Entretanto, é necessário levar em conta que esses valores estão diluídos em várias atividades, não se podendo analisar a variação dos valores destinados a iniciativas contraterroristas. Também em relação à Colômbia e ao México é perceptível a mesma tendência de queda: quanto ao CTFP, o país andino teve uma redução de US \$1,2 milhões para US\$ 879 mil no valor transferido, enquanto o segundo teve uma diminuição de US\$ 917,1 milhões para US\$ 737 mil (SECURITY ASSISTANCE MONITOR, 2018a).

Já em relação à assistência antidrogas, foi observada uma quantidade maior de programas, ainda que o International Narcotics Control and Law Enforcement (INCLE) seja o principal programa destinado a esse fim. Quanto a este, houve um aumento no montante da assistência destinada aos países da região, subindo de US\$ 602,3 milhões para US\$ 749,4 milhões entre 2010 e 2016. Por outro lado, os dois outros programas de assistência contra o narcotráfico - as Seções 1004 e 1033 de Assistência Antidrogas - tiveram uma queda de US\$ 408,5 milhões para US\$ 155,2 milhões e de US\$ 53 milhões para US\$24,3 milhões, respectivamente5 (SECURITY ASSISTANCE MONITOR, 2018a).

Os valores repassados a Colômbia e México acompanham a mesma variação descrita, tendo um aumento nos valores transferidos através da INCLE e uma queda nos das Seções 1004 e 1033. Entretanto, quando os valores dos três programas são somados, o que se vê é que a queda nos dois últimos não é compensada pelo aumento do orçamento da INCLE, havendo, portanto, uma queda de US\$ 1,06 bilhão para US\$ 904,6 milhões no valor total destinado à assistência antidrogas para a América Latina. Por outro lado, também é interessante notar que o número de efetivos latinoamericanos treinados pelos EUA teve um aumento, passando de 12.491 para 17.244 (SECURITY ASSISTANCE MONITOR, 2018b). Já no que tange aos dados relativos à importação de armamentos norte-americanos pelos países da América Latina, também foi verificada uma tendência de queda entre 2009 e 2016, passando de US \$ 4,6 bilhões para US\$ 754,9 milhões (SECURITY ASSISTANCE MONITOR, 2018c).

A análise dos valores destinados tanto à assistência de segurança em geral quanto ao combate antiterrorismo e antidrogas revela que, embora tenha havido uma queda geral nas transferências de recursos do governo norte-americano para a região latino-americana, o que se verifica é uma queda

5 Os valores para a Seção 1033 vão apenas até 2014. 
menor no valor destinado à assistência antidrogas que, por si só, já se encontrava em valores absolutos altos em relação à ajuda antiterrorista. Ao mesmo tempo, esse valor na ajuda para o combate às drogas permanece alto, não sofrendo uma redução drástica no seu montante. Portanto, percebe-se que há uma ênfase maior no combate às drogas destinado pela política de segurança dos EUA para a América Latina do que no combate ao terrorismo internacional.

Esses resultados podem ser explicados pela mudança do foco da política de segurança estadunidense para a região que, diferentemente do governo Bush (que a enquadrou na guerra global ao terror), privilegiou as ações relacionadas à segurança cidadã (TOKATLIAN, 2015). Esse conceito, por sua vez, ensejava uma ênfase menor nas ações militares internas nesses países e um maior foco na implementação de projetos socioeconômicos, como se verá mais adiante. Ao seu turno, a diminuição nos fluxos de armamentos para a região e o crescimento da quantidade de efetivos latinoamericanos treinados por instrutores estadunidenses demonstram que o foco da política de segurança dos EUA para a América Latina parece ter enfatizado mais os aspectos indiretos de auxílio na área de segurança, com foco maior na influência via treinamento de unidades militares e de outras instituições de segurança - como se verá mais adiante, principalmente nos casos da Colômbia e da América Central.

Partindo para a análise dos casos escolhidos para estudo, no que se refere ao Plano Colômbia, apesar de os EUA terem continuado a apoiar os esforços contrainsurgentes das Forças Armadas do país andino, houve uma mudança no foco desse programa. Desse modo, ao invés da forte ênfase na militarização da ajuda norte-americana por meio da transferência de equipamentos militares (sobretudo aeronaves), buscou-se uma abordagem mais ligada à realização de atividades subsidiárias ${ }^{6}$ pelas Forças Armadas e pelas agências de segurança pública, com foco na Doutrina de Ação Integral e no desenvolvimento de projetos de desenvolvimento socioeconômico em áreas antes afligidas pelo conflito armado.

Assim, o governo norte-americano continuou a auxiliar financeiramente o Centro de Coordenação de Ação Integral da Colômbia, responsável por adiantar projetos de desenvolvimento para regiões no interior do país e contribuiu com a transferência de US\$ 227 milhões para o Plano de Consolidação do governo Uribe entre 2010 e 2011 (ISACSON, 2012). Além disso, a administração Obama continuou a auxiliar o governo colombiano com a Iniciativa de Desenvolvimento Estratégico da Colômbia (CSDI, na sigla em inglês), cuja finalidade era respaldar o Plano Nacional de Consolidação do governo colombiano - essa iniciativa durou até 2013, tendo somado US\$172.883 (USA, 2012). Cabe ressaltar que essas mudanças na cooperação com a Colômbia foram iniciadas no final da administração Bush, mas foram intensificadas no período de Barack Obama.

\footnotetext{
${ }^{6}$ Ações subsidiárias são entendidas como aquelas que não estão ligadas à ação armada desempenhada pelas forças militares de determinado país.
} 
Um importante componente desse período foi a atuação cada vez maior da Agência dos EUA para o Desenvolvimento Internacional (USAID) $7 \mathrm{em}$ apoio à implementação de projetos socioeconômicos, principalmente através do direcionamento de capitais privados para serem investidos nessas ações. Além do próprio CSDI, que foi coordenado pela USAID, a agência também implementou uma Estratégia de Cooperação de Desenvolvimento do País (CDCS, na sigla em inglês) entre 2014 e 2018, um programa de assistência dividido em quatro principais categorias: presença de instituições estatais nas áreas-alvo; reconciliação entre as vítimas, ex-combatentes e outros cidadãos; melhora nas condições para o crescimento econômico rural e preservação ambiental. Por meio dessa iniciativa, os dirigentes dessa agência destinaram cerca de US\$ 150 bilhões para investimentos em projetos em territórios marginalizados, desenvolvidos em parceria com o governo colombiano. Desse modo, além de ONGs nacionais e transnacionais, uma importante parcela da contribuição veio em forma de investimentos de empresas transnacionais pertencentes a diversos segmentos: engenharia, análise de mercado, produção agrícola, dentre outros (UNITED STATES OF AMERICA, 2014a).

Outra iniciativa que também foi importante nesse momento para financiar projetos de desenvolvimento socioeconômico em apoio à implementação do Acordo de Havana ${ }^{8}$ foi denominada Paz Colômbia9 - que substituiu o Plano Colômbia a partir de 2016. Seu montante foi de US\$ 391,3 milhões, distribuídos em cinco principais categorias: US \$ 180 milhões para projetos de construção de governança em áreas afetadas pelo conflito armado, substituição de cultivos e assistência às vítimas; US\$ 143 milhões para a erradicação manual de cultivos de coca, apoio à Polícia Nacional e reforma do setor judiciário; US \$ 10 milhões para que as forças de segurança colombianas treinassem contrapartes em outros países; US\$ 38,5 milhões para apoio às Forças Armadas colombianas; e US\$ 21 milhões para programas de desminagem (BEITTEL, 2017).

Nesse período também foi desenvolvido o Plano de Ação EUA-Colômbia para Segurança Regional (USCAP, na sigla em inglês). Essa iniciativa foi iniciada em 2013 e consistia em uma cooperação triangular para o treinamento de militares e policiais de terceiros países por oficiais colombianos com assistência financeira e logística do Comando Sul dos EUA. Importante notar que a maioria dos efetivos treinados pela Colômbia consistia em membros das forças de segurança da América Central e Caribe, configurando o que Tickner e Morales (2016) denominaram "cooperação em segurança por procuração", consistindo por sua vez em um caso de dependência das Forças Armadas colombianas em relação às dos EUA (TICKNER; MORALES, 2016). Desse modo, entre

\footnotetext{
7 Essa agência está ligada ao Departamento de Estado dos EUA e tem como objetivo formal realizar programas de cooperação de desenvolvimento socioeconômico com outros países, sobretudo os periféricos.

8 Esse acordo foi assinado entre o governo colombiano e as FARC em 2016 e marcou o fim do conflito armado entre o Estado e essas forças guerrilheiras, que se desmobilizaram em 2017, transformando-se em um partido político.

9 O Plano Colômbia foi criado em 2000 e consistiu, basicamente, em um pacote de assistência antidrogas e contrainsurgente. Seu conteúdo consistia fundamentalmente de fornecimento de tecnologia militar, treinamento e repasse de recursos financeiros para as Forças Armadas e a Polícia Nacional (ROJAS, 2014).
} 
2013 e 2016, o número de pessoal da América Central treinado por técnicos colombianos através da assistência norte-americana foi de 11.181 indivíduos (BEITTEL, 2017).

No caso do México, apesar de a Iniciativa Mérida ter continuado a ser executada, houve mudanças importantes em sua constituição que atestam uma diminuição da ênfase militarista do governo Bush. Esse programa foi apresentado como uma iniciativa bilateral entre os governos estadunidense e mexicano em 2007 e começou a ser aplicado em 2008; seu foco era no combate ao crime organizado principalmente nas regiões de fronteira entre os dois países. Desse modo, foram estabelecidos quatro pilares para o programa: combate aos grupos criminosos organizados; institucionalização da garantia da lei aliada à proteção dos direitos humanos; criação de uma "fronteira do século XXI"; e construção de comunidades fortes e resilientes (SEELKE; FINKLEA, 2017).

A partir de 2011, o governo Obama realizou uma revisão da estratégia da Iniciativa Mérida, decidindo juntamente com o governo mexicano "expandir o escopo dos esforços bilaterais para focar na construção de instituição através de transferências tecnológicas, desenvolvimento econômico e programas sociais baseados na comunidade, estados e municipalidades" (SEELKE; FINKLEA, 2017, p. 9). Assim, desde 2011, o segundo pilar - construção da garantia da lei concomitante ao respeito dos direitos humanos - foi o que mais recebeu foco da assistência norte-americana, sendo que, no governo anterior, a ênfase recaía no combate aos grupos criminosos organizados. Ao mesmo tempo, a partir desse mesmo ano, o montante da assistência norte-americana destinada ao aspecto militar passou a diminuir e em 2012 ele deixou de existir. Além disso, o valor repassado pelo programa INCLE também diminui, passando de US\$ 365 milhões para US\$ 100 milhões entre 2010 e 2016. Enquanto isso, o montante destinado à ajuda econômica cresceu significativamente, passando de US\$ 9 milhões para US\$ 39 milhões nesse mesmo espaço de tempo (SEELKE; FINKLEA, 2017).

Além dessa mudança na estratégia geral da Iniciativa Mérida, também no caso mexicano a USAID e o Escritório de Assuntos de Narcóticos Internacionais e Aplicação da Lei (INL, na sigla em inglês) - ligado ao Departamento de Estado - foram responsáveis pela implementação de iniciativas voltadas para o desenvolvimento socioeconômico de regiões de fronteira e outras áreas com alto índice de criminalidade. Entre 2014 e 2018, essas instituições implementaram 445 projetos dentro do escopo da Iniciativa Mérida, sendo 388 realizados pelo INL e 57, pela USAID. A maioria dos recursos do primeiro foram direcionados para apoio à reforma do setor do sistema de justiça criminal do México, segurança de fronteiras e portos, profissionalização da polícia e atividades antinarcóticos (incluindo apoio aos militares); já os recursos da segunda foram usados em projetos de aplicação da lei, garantia de direitos humanos, transparência governamental e prevenção do crime e da violência (USA, 2019).

Também como no caso colombiano, o México recebeu assistência de segurança da USAID através da criação de uma CDCS. Esse programa foi dividido em quatro categorias: prevenção do crime e da violência, aplicação da lei, garantia dos direitos humanos e combate à mudança climática. 
O total dos recursos de assistência da USAID para o México nesse período consistiu em U\$222,7 milhões para esses projetos. Além dos valores advindos de ONGs nacionais e transnacionais, bem como de fundos do Partido Democrata e do Partido Republicano, também foram garantidos recursos de empresas transnacionais pertencentes a setores como finanças, engenharia, análise de mercado, tecnologia verde, dentre doutros (UNITED STATES OF AMERICA, 2014b).

Outro ponto importante para a política de segurança do governo Obama no que concerne ao México foi o combate à imigração ilegal. Nesse ponto, pode ser visto também a tendência a uma menor transferência de recursos especificamente militares dos EUA para o Estado mexicano em favor da execução de programas de cunho social - o que não significou, porém, uma redução no emprego das forças de segurança do país latino-americano nas regiões de fronteira. Isso pode ser visto a partir de um dos pilares da "nova fase" da Iniciativa Mérida, qual seja, o de criação de uma fronteira do século XXI. Assim, foram criados o programa Comunidades Seguras, que incluía a coordenação entre as polícias federais, estaduais e locais e Agência de Imigração e Aduanas (ICE, em inglês). Também foi elaborada a iniciativa Fronteira Sul, na fronteira do México com Guatemala e Belize e que envolveu a cooperação bilateral entre agências estatais para a patrulha contra imigrantes ilegais (VILLAFUERTE; GARCÍA, 2017).

Além disso, a USAID e o INL passaram a destinar maiores somas de recursos privados para a reconstrução de comunidades de fronteira, a fim de impedir que os indivíduos migrassem para os EUA. Por sua vez, os dois países formaram novos órgãos militares de ação conjunta contra imigração ilegal, como foram os casos das Conferências de Comandantes Regionais de Fronteiras e do Grupo de Cooperação de Segurança Bilateral. Também houve uma aproximação entre as forças armadas de ambos países, inclusive para apoiar o desenvolvimento do sistema de vigilância aérea do país latinoamericano (GUEVARA Y MOYANO, 2018).

Desse modo, tanto para Colômbia quanto para México foram destinados recursos para projetos de desenvolvimento socioeconômico que completassem o processo de estabilização da segurança de áreas afetadas pelo conflito armado (no caso colombiano) e pelo crime organizado (no mexicano). Além disso, em ambos os casos, essas ações dos órgãos estadunidenses estiveram ligadas às políticas de segurança da Colômbia e do México, respectivamente, o Plano de Defesa e Segurança Todos por um Novo País e o Plano Setorial de Defesa Nacional 2013-2018. Entretanto, em que pese tenham sido construídas iniciativas de desenvolvimento socioeconômico nessa fase das relações entre EUA e México, isso não significou a diminuição do uso de forças militares em matéria de segurança interna.

Para além dessas iniciativas já em andamento, foram criados dois novos programas de cooperação em segurança, dessa vez com os países da América Central e do Caribe. O primeiro foi denominado Iniciativa de Segurança Regional da América Central (CARSI), tendo sido criado em 2010. Suas linhas de ação consistiam em: 1) promoção da prosperidade e da integração regional; 2) fortalecimento da governança; e 3) aumento da segurança. O CARSI envolve uma grande quantidade 
de agências norte-americanas (USAID, Departamento de Estado, Departamento do Tesouro, Comando Sul, dentre outros); entretanto, o grosso das ações foram realizadas pela USAID. Seu escopo de ações foi desenhado para abarcar capacitações regionais para as elites políticas dos países centro-americanos, equipamento e treinamento das forças de segurança (polícias e forças armadas) principalmente visando o combate ao narcotráfico. Entretanto, sua ênfase passou a ser cada vez mais voltada para a assistência ao desenvolvimento econômico e a iniciativas civis de combate ao narcotráfico, tendo também havido aí uma queda no componente militar do programa (MEYER, 2019).

De um modo geral a assistência norte-americana para a América Central por meio do CARSI abrangeu a reforma do setor de segurança, ou seja, a influência nas diversas instituições estatais ligadas à esfera securitária, como forças armadas, polícias, órgãos do Judiciário, agências de inteligência, dentre outros. Além disso, agências de segurança dos EUA (FBI, DEA e o Departamento de Segurança Interna) estabeleceram programas de treinamento com diversas unidas das forças públicas desses países, voltados principalmente para o combate a grupos ligados ao crime organizado transnacional (OLSON; ZAINO, 2015).

Por outro lado, também a USAID teve importante participação na elaboração e execução dos projetos de desenvolvimento socioeconômico, por meio da Estratégia de Cooperação de Desenvolvimento Regional para América Central e México (2015-2019), que esteve alinhada à Estratégia de Engajamento dos EUA na América Central, também desenvolvida no governo Obama, a fim de garantir maior estabilidade para os países da região. Esse programa envolveu quatro objetivos principais: aumento da integração econômica regional; melhora do crescimento econômico sustentável; aumento da segurança cidadã; e melhora na saúde dos países centro-americanos (MEYER, 2019).

Também cabe mencionar que a assistência de segurança dos EUA para a América Central também esteve acompanhada de medidas anti-imigração, especialmente para os países do chamado Triângulo do Norte (Belize, Guatemala e Honduras), que são responsáveis por uma grande quantidade de imigrantes indocumentados que se dirigem para o território norte-americano por meio da fronteira norte do México. Esse componente anti-imigração tem sido constituído tanto pelo uso de forças de segurança no México e nos EUA para barrar a passagem desses indivíduos quanto pela implementação de programas de desenvolvimento socioeconômico nesses países. Desse modo, por meio de agências como o Departamento de Estado, a USAID e o Departamento de Segurança Interior, o governo Obama realizou iniciativas de melhora na infraestrutura escolar, técnicas de agricultura, ações de reabilitação de jovens, dentre outros. Essas iniciativas foram acompanhadas de maiores investimentos em patrulha de fronteiras e ajuda às forças de segurança locais nesses países (UNITES STATES OF AMERICA, 2015a). Portanto, assim como no caso mexicano, a imigração foi um dos temas principais da política de segurança norte-americana para a América Central, abrangendo também assistência não-militarizada. 
A Iniciativa de Segurança da Bacia do Caribe (CBSI, na sigla em inglês) foi criada em 2009 como um mecanismo de cooperação entre os EUA e os países da Bacia do Caribe, tendo como objetivos "reduzir o tráfico de ilícitos na região, avançar a segurança pública e promover justiça social" (UNITED STATES OF AMERICA, 2019, p. 1). O programa foi concebido e implementado em coordenação com o Escritório do Departamento de Estado de relação do Hemisfério Ocidental e sua implementação tem sido feita pelo Departamento de Estado, pela USAID e pelo Departamento de Defesa. Seu foco recai sobre cinco áreas: cooperação em segurança aérea e marítima; construção de capacidade de garantia da lei; segurança de fronteiras e portos e interdição de armas de fogo; e reforma do setor de justiça e prevenção contra o crime nas populações jovens em área de risco. Apesar de seu componente militar ter iniciado em um valor relativamente alto entre 2010 e 2012, esse patamar começou a diminuir a partir de 2013, indo de US\$ 14,5 milhões para US\$ 75 milhões entre 2010 e 2016. Por outro lado, a assistência econômica apresentou crescimento, indo de US\$ 14 milhões para US\$ 25 milhões (SULLIVAN, 2019).

Tendo em vista os dados analisados nesta seção foi possível compreender que a política de segurança do governo de Barack Obama para a América Latina foi caracterizada por um duplo movimento que envolveu, de um lado, a redução dos níveis de assistência especificamente militar para a região e, particularmente, para os quatro casos analisados. De outro, foi vista uma tendência de redirecionamento dos programas de assistência de segurança para uma dimensão mais relacionada com a promoção do desenvolvimento socioeconômico em áreas afetadas pela violência, seja de grupos guerrilheiros, seja de grupos atuantes no crime organizado. Além disso, também nesse período vê-se uma diminuição dos recursos destinados ao auxílio no combate ao terrorismo - que havia sido intensificado no governo Bush.

Desse modo, com base nesses resultados, seria possível falar de uma mudança tática dos EUA na manutenção de relações hegemônicas de poder na América Latina em sua dimensão securitária. De um modo geral, enquanto a literatura indica que a política de segurança do governo Bush esteve ligada a um aumento no número de recursos financeiro, tecnológicos, bem como de treinamento destinados às forças armadas da região - inclusive nos casos do Plano Colômbia e da Iniciativa Mérida -, no governo Obama, a ação política do Estado norte-americano esteve ligada a uma postura mais "branda", porém sem deixar de lado o componente militar, empregado no combate a ameaças internas nos países da região. Dessa forma, em que pese a postura norte-americana tenha continuado a ser de influenciar as forças armadas e os demais aparatos coercitivos dos Estados latino-americanos, esse processo foi revestido de novas características, ajustadas tanto às mudanças estruturais a nível internacional quanto às próprias idiossincrasias das elites políticas norteamericanas. 


\section{CONSIDERAÇÕES FINAIS}

O presente trabalho teve como objetivo compreender as mudanças na política de segurança dos EUA para a América Latina durante os dois mandatos de Barack Hussein Obama (2009-2017). A pesquisa realizada partiu da perspectiva de que as relações de poder entre os EUA e os países latino-americanos no período posterior ao da Guerra Fria podem ser consideradas como sendo uma hegemonia. Nesse sentido, compreende-se que relações hegemônicas de poder são desenvolvidas pelas elites políticas do país dominante sobre a sociedade do dominado, com anuência das elites dirigentes desse último. Por sua vez, essas relações de poder podem manifestar-se em diferentes dimensões, sendo as principais: econômica, político-institucional, militar e ideológica.

Entretanto, ainda sob respaldo da literatura sobre relações entre EUA e América Latina no pós-Guerra Fria, a manifestação da hegemonia estadunidense, conquanto seja contínua, não tem sido invariável ao longo do tempo, apresentando ajustes pontuais no tipo de ação política levada a cabo para manter esse tipo de relação de poder. Nesse sentido, van Apeldoorn e de Graaf (2014) citam como a grande estratégia norte-americana apresentou mudanças ao longo do tempo, apesar de manter a mesma finalidade de executar o que eles chamam de "política de portas abertas", ou seja, a manutenção de uma ordem econômica internacional liberal, caracterizada pela abertura dos fluxos econômicos financeiros e de mercadorias. Nesse sentido, entende-se que também no caso das relações com os países latino-americanos, as elites políticas têm ajustado sua política de segurança para manter a ordem hegemônica.

Dessa maneira, é entendido que, ao invés de um declínio da hegemonia norte-americana nas décadas de 2000 e 2010, como afirmam Kassab (2016), Tulchin (2016) e O’Keefe (2018), seria mais correto falar de um ajuste nas ações norte-americanas para manter esse tipo de relação de poder com os países da região. Assim, foi visto neste trabalho que a política de segurança dos EUA no governo Obama adotou uma postura diferente com relação àquela adotada por George Bush (2002-2009). Em primeiro lugar, foi visto uma diminuição na tendência de militarização da abordagem estadunidense, refletida na diminuição dos repasses de recursos destinados especificamente à área militar, tanto na região como um todo quanto nos quatro estudos de caso analisados. Também foi visto que o fluxo de armamentos para a região também declinou, apesar de ter sido registrado um aumento na quantidade de efetivos da região que foram treinados por instrutores norte-americanos.

É importante ressaltar que quando se fala de militarização não se está querendo dizer que houve uma ausência ou diminuição do emprego de militares latino-americanos em atividades de segurança interna, como no combate ao crime organizado - especialmente ao narcotráfico - e à imigração ilegal. Ao invés disso, o termo é empregado para falar da característica geral da assistência de segurança dos EUA para a região. Como foi visto, o governo Obama foi marcado, simultaneamente, pela diminuição da assistência estritamente militar, tanto em termos de recursos financeiros quanto de fornecimento de tecnologia, e pelo aumento dos recursos empregados em 
iniciativas civis, como no caso dos projetos de desenvolvimento socioeconômico capitaneados pelos órgãos do Departamento de Estado. Apesar disso, é preciso mencionar, foi mantida a tendência de militarização da segurança interna dos países da região, com emprego das forças armadas nas tarefas que institucionalmente são de atribuição policial.

Em segundo lugar, também foi visto menor ênfase no discurso de combate ao terrorismo, focado na intensificação do uso dos aparelhos coercitivos sobre parcelas da sociedade. Esse discurso foi substituído pelo de "segurança cidadã", focado em uma abordagem mais "branda" em relação à administração anterior, mas sem abdicar do emprego interno das forças de segurança na região. Por fim, a assistência de segurança estadunidense nesse período teve um foco maior na implementação de projetos de promoção ao desenvolvimento socioeconômico em áreas marginalizadas e afetadas pela violência, seja pelo conflito armado interno (no caso da Colômbia e, em menor medida, no do México), seja pela atuação de grupos ligados ao crime organizado transnacional (casos de México, América Central e Caribe). Desse modo, durante a administração Obama, a USAID desempenhou um papel ainda mais central na execução da política de segurança norte-americana para a América Latina.

Portanto, tendo em vista os dados analisados referentes às ações tomadas pelas elites políticas ligadas ao governo Obama para a América Latina na área de segurança, pode-se compreender que a hipótese inicial de que as mudanças postas em marcha consistiram em ajustes táticos para a manutenção das relações hegemônicas de poder (objetivo estratégico) foi corroborada. Desse modo, a política de segurança do governo Obama esteve fundamentalmente voltada para a implementação de iniciativas que integrassem, de um lado, o emprego das forças de segurança dos Estados latino-americanos contra focos de instabilidade representados principalmente por agentes do crime organizado transnacional e, de outro, a realização de projetos de desenvolvimento socioeconômico que permitissem a reconstrução econômica e o controle institucional por parte do Estado em territórios antes afetados por grupos armados internos. Por sua vez, tanto o emprego coercitivo das forças de segurança quanto a implementação de iniciativas sociais e econômicas estiveram ligados à criação de uma ordem interna minimamente estável nos países latinoamericanos

*Artigo recebido em 22 de março de 2021, aprovado em 20 de maio de 2021.

\section{REFERÊNCIAS}

AVILÉS, William. Globalization and Military Power in the Andes. New York: Palgrave Macmillan, 2010. 
AVILÉS, William. The drug war in Latin America: hegemony and global capitalism. Abingdon, Oxon ; New York: Routledge, 2017.

AYERBE, Luis Fernando. Estados Unidos e América Latina: a construção da hegemonia. São Paulo: Editora Unesp, 2002.

AYERBE, Luis Fernando. Ejes estratégicos de la política exterior para América Latina y el Caribe en los gobiernos de George W. Bush y Barack Obama. Clío América, Santa Marta, v. 4, n. 7, p.9-35, 2010.

BEITTEL, June S.. Colombia: Background and U.S. relations. Washington, D.C: Congress Research Service, 2017.

BEITTEL, June S.. Mexico: organized crime and drug trafficking organizations. Washington, D.C: Congress Research Service, 2019.

BIEGON, Rubrick. US Power in Latin America: renewing hegemony. New York: Routledge, 2017.

BURTON, Joe. Nato's durability in a post-cold war world. [s.l.]: SUNY Press, 2019.

BROOKE-HOLLAND, Louisa. NATO's military response to Russia: November 2016 update. [s.l.]: House of Commons Library, 2016.

CHODOR, T. Neoliberal hegemony and the Pink Tide in Latin America: breaking up with TINA? Basingstoke; New York: Palgrave Macmillan, 2015.

CLINTON, Hillary. America's Pacific Century. Foreign Policy, Washington, D.C., 2011.

DEL PERO, Mario. Dollars, Arms, Words: Barack Obama and the Dilemmas of American Hegemony. ERIS - European Review of International Studies, n. 2-2018, p. 24-40, 2019.

DESCH, Michael C. The More Things Change, the More They Stay the Same: The Liberal Tradition and Obama's Counterterrorism Policy. PS: Political Science \& Politics, v. 43, n. 03, p. 425-429, 2010.

GUEVARA Y MOYANO, Iñigo. More than neighbors: New developments in the institutional strengthening of Mexico's Armed Forces in the context of U.S.-Mexican military cooperation. Washington, D.C.: Woodrow Wilson Center, 2018.

ISACSON, Adam. Consolidating "Consolidation". Washington, D.C: Washington Office On Latin America, 2012.

JERVIS, David. Obama and the Middle East. Teka Komisji Politologii i Stosunków Międzynarodowych, v. 12, n. 2, p. 31-57, 2017.

KALDOR, Mary. El arsenal barroco. Madri: Siglo XXI, 1986.

KASSAB, Hanna S.. The Hemisphere and Declining U.S. Hegemony. In: BAGLEY, Bruce; ROSEN, Jonatha; KASSAB, Hanna S. (Org.). Reconceptualizing Security in the Americas in the Twenty-First Century. New York: Lexington Books, 2015, p. 3 - 23.

LOWENTHAL, Abraham F. The Obama Administration and the Americas. In: Shifting the Balance: Obama and the Americas. Washington, D.C.: Brookings Institution Press, 2011, p. 128. 
LYMAN, Rick. Eastern Europe Cautiously Welcomes Larger U.S. Military Presence. The New York Times, 2016. Disponível em: <https://www.nytimes.com/2016/o2/o3/world/europe/easterneurope-us-military.html>. Acesso em: 19 Mar. 2021.

MANYIN, Mark E.. Pivot to the Pacific? The Obama Administration's "Rebalancing"

Toward Asia. Washington, D.C: Congressional Research Service (CRS), 2012.

MEYER, Peter J. U.S. Strategy for Engagement in Central America: Policy Issues for Congress. Washington, D.C.: Congress Research Service, 2019.

O'KEEFE, Thomas Andrew. Bush II, Obama, and the Decline of U.S. Hegemony in the Western Hemisphere. New York: Routledge, 2018.

OLSON, Eric L. ; ZAINO, Christine. The Central America Regional Security Initiative - Losing the Good Fight: When Good Intentions are Not Enough. In: OLSON, Eric L. (Org.). Crime and violence in Central America's Northern Triangle: how U.S. policy responses are helping, hurting, and can be Improved. Washington, D.C.: Woodrow Wilson Center, 2015, p. 19-53.

PECEQUILO, Cristina Soreanu; FORNER, Clarissa Nascimento. Obama e América Latina (2009/2016): estagnação ou avanços?. Monções: Revista de Relações Internacionais da UFGD, Dourados, v. 6, n. 11, p.370-394, 2017a.

PECEQUILO, Cristina S.; FORNER, Clarissa N.. Barack Obama e o Oriente Médio: Um Panorama Crítico (2009/2017). Revista Carta Internacional, Belo Horizonte, v. 12, n. 2, p.101-125, 2017 b.

PICCOLLI, Larlecianne. Europa enquanto condicionante da política externa e de segurança da Rússia: o papel da defesa antimíssil. Dissertação, UFRGS, 2012.

ROBInson, William I.. Promoting Poliarchy: globalization, us intervention, and hegemony. Cambridge: Cambridge University Press, 1996.

ROBINSON, William I.. Latin America and Global Capitalism: A Critical Globalization Perspective (Johns Hopkins studies in globalization). [S. l.]: Johns Hopkins University Press, 2008.

ROJAS, Diana Marcela. El Plan Colombia: la intervención de Estados Unidos en el conflicto armado colombiano (1998-2012). Bogotá: IEPRI, 2014.

SECURITY ASSISTANCE MONITOR (SAM). U.S. Security Aid to Latin America. 2018a. Disponível em: <http://securityassistance.org/data>. Acesso em: 30 out. 2020.

SECURITY ASSISTANCE MONITOR (SAM). Latin American Trainees. 2018b. Disponível em: <http://securityassistance.org/content/trainees-dashboard>. Acesso em: 30 out. 2020.

SECURITY ASSISTANCE MONITOR (SAM). Arms Sales. 2018c. Disponível em: <http://securityassistance.org/content/trainees-dashboard>. Acesso em: 30 out. 2020.

SEELKE, Clare R.; FINKLEA, Kristin. U.S.-Mexican Security Cooperation: The Mérida Initiative and Beyond. Washington, D.C: Congressional Research Service (CRS), 2017a.

SUlLIVAN, Mark P. Caribbean Basin Security Initiative. Washington, D.C.: Congress Research Service, 2019. 
TICKNER, Arlene B.; MORALES, Mateo. Cooperación dependiente asociada: Relaciones estratégicas asimétricas entre Colombia y Estados Unidos. Colombia Internacional, Bogotá, v. 85, n. 1, p.171-205, 2015.

TOKATLIAN, J. G. The War on Drugs and the Role of SOUTHCOM. In: BAGLEY, B.; ROSEN, J. (org.). Drug Trafficking, Organized Crime, and Violence in the Americas Today. [S. l.]: University Press of Florida, 2015.

TULCHIN, Joseph. Latin America in International Politics: Challenging U.S. Hegemony. Colorado: Lynne Rienner, 2016.

UNITED STATES OF AMERICA (USA). Colombia programa at-a-glance. Washington, D.C: U.S. Agency to International Development (USAID), 2012.

UNITED STATES OF AMERICA (USA). National Security Strategy. Washington, D.C: White House, 2010.

UNITED STATES OF AMERICA (USA). Colombia Country Development Cooperation Strategy 2014-2018: a path to peace. Washington, D.C: U.S. Agency to International Development (USAID), 2014a.

UNITED STATES OF AMERICA (USA). Mexico Country Development Cooperation Strategy 2014-2018: a path to peace. Washington, D.C: U.S. Agency to International Development (USAID), 2014b.

UNITED STATES OF AMERICA (USA). National Security Strategy. Washington, D.C: White House, 2015a.

UNITED STATES OF AMERICA. Central America: Information on Migration of Unaccompanied Children from El Salvador, Guatemala, and Honduras. Washington, D.C.: General Accounting Office (GAO), 2015.

UNITED STATES OF AMERICA (USA). U.S. Assistance to Mexico: State and USAID allocated over $\$ 700$ million to support criminal justice, border security, and related efforts from fiscal year 2014 through 2018. Washington, D.C: Government Accountability Office (GAO), 2019.

UNITED STATES OF AMERICA (USA). Caribbean Basin Security Initiative. Washington, D.C: Congressional Research Service (CRS), 2019.

VAN APELDOORN, B.; DE GRAAFF, N. Corporate elite networks and US post-Cold War grand strategy from Clinton to Obama. European Journal of International Relations, [S. l.], v. 20, n. 1, p. 29-55, 2012.

VILLAFUERTE, D.; GARCÍA, M. del C. La política antimigrante de Barack Obama y el programa Frontera Sur: consecuencias para la migración centroamericana. Migración y Desarrollo, [S. l.], v. 15, n. 28, p. 39-64, 2017. 